Research Article

\title{
Seismic Behavior Analysis of Damaged Steel Fiber-Reinforced High-Strength Concrete Frame Joints Strengthened by FRP
}

\author{
Wang Tingyan $\mathbb{D}^{1,2}$ Zhou Yun, $^{1}$ and Zhang Junwei ${ }^{3}$ \\ ${ }^{1}$ School of Civil Engineering, Guangzhou University, Guangzhou 510006, China \\ ${ }^{2}$ North China University of Water Resources and Electric Power, Zhengzhou 450045, China \\ ${ }^{3}$ Henan Agricultural University, Zhengzhou 450002, China \\ Correspondence should be addressed to Wang Tingyan; 124466715@qq.com
}

Received 8 April 2020; Revised 20 June 2020; Accepted 21 September 2020; Published 8 October 2020

Academic Editor: Peng Zhang

Copyright (c 2020 Wang Tingyan et al. This is an open access article distributed under the Creative Commons Attribution License, which permits unrestricted use, distribution, and reproduction in any medium, provided the original work is properly cited.

In this paper, the seismic behavior of fiber-reinforced polymer (FRP) strengthened and unstrengthened steel fiber-reinforced high-strength concrete frame joints under low cyclic loading was tested. Then, the nonlinear finite element program was used to simulate the seismic behavior of FRP strengthened and unstrengthened steel fiber-reinforced high-strength concrete frame joints under low cyclic repeated load. The influence of FRP bond direction on the seismic behavior of steel fiber-reinforced high-strength concrete frame joints was studied. Through the comparison of the test values and numerical simulation values of the hysteretic curve, skeleton curve, energy dissipation capacity, displacement ductility, bearing capacity degradation, stiffness degradation, and other performance indexes of frame joints, the rule was obtained. The results showed that the $45^{\circ}$ bonding direction of carbon fiber cloth is better than the $0^{\circ}$ bonding direction, and the digital simulation results are in good agreement with the test results. Therefore, the constitutive model, element, end constraint, and loading method used in the finite element numerical simulation of this paper were reasonable, which can provide reference for the similar research in the future.

\section{Introduction}

Frame joint is an important and key part of frame structure. A node is not only the pivot of transferring and distributing internal force but also plays an important role in the whole structure without collapse. Once the frame joint is destroyed, it is easy to cause the collapse of the whole structure. In the high-strength concrete frame structure, although the highstrength concrete can greatly improve the bearing capacity of the concrete structure, it cannot significantly improve the crack resistance and ductility of the concrete structure. Many earthquake disasters at home and abroad show that, under the action of earthquake, the joint area is still the most vulnerable part of the high-strength concrete frame structure, and its damage often leads to the collapse of the whole building structure [1]. Therefore, to improve the ductility of joints and avoid joint failure is the goal of our seismic design $[2,3]$.
The mechanical properties of concrete, such as tension, bending, shear, and torsion, can be significantly improved by adding fiber into concrete. Fiber can also significantly improve the ductility, toughness, energy consumption, and other deformation properties of concrete. Especially in the high-strength concrete structure, the interface bonding performance between the high-strength concrete and the steel fiber is better, and the steel fiber distribution in the high-strength concrete can play a more active role. Therefore, adding steel fiber into high-strength concrete frame joints is an effective measure to improve the mechanical properties of frame joints, improve the reinforcement crowding, and reduce the construction difficulty. Therefore, adding steel fiber into the joints of high-strength concrete frame should play a positive role in improving the seismic performance of the joints $[4,5]$.

Although steel fiber can improve the ductility and stress of high-strength reinforced concrete frame joints, steel 
fiber-reinforced high-strength concrete frame joints are still unable to avoid damage in the midium and large earthquakes. After the earthquake, the steel fiber-reinforced highstrength concrete frame joints still need to be strengthened $[6,7]$. Fiber-reinforced polymer (FRP) reinforcement technology, as a newly developed reinforcement method with high-performance materials, has attracted great attention at home and abroad due to its advantages of convenient construction, high strength and efficiency, and good durability $[8,9]$. Therefore, this paper uses FRP to strengthen the damaged steel fiber-reinforced high-strength concrete frame joints. In this paper, the seismic behavior of damaged SFRHC frame joints strengthened by FRP under low cycle repeated load is studied by experiment and numerical simulation. The influence of the FRP bonding direction on the seismic behavior of frame joints is analyzed, and some valuable conclusions are obtained.

\section{The Experimental Conditions}

2.1. Design of the Model. The frame joint model adopted the side joint between the end column of the middle story and the frame beam. The size and reinforcement drawing, designed according to the Code for Design of Concrete Structures (GB50010-2010), are shown in Figure 1 [10]. The steel fiber used for experiment was ingot milling fiber (AMI04-32-600) with the volume ratio of $1.0 \%$, length diameter ratio of $35 \sim 40$, equivalent diameter of $0.94 \mathrm{~mm}$, tensile strength $\geq 700 \mathrm{MPa}$, and adulteration range of $125 \mathrm{~mm}$ and $50 \mathrm{~mm}$, respectively, in the beam end and two sides of the pillar end at the core area. The cement used was 42.5 \# high-strength Portland cement. The maximum particle size of the stone was $20 \mathrm{~mm}$. The fineness modulus of medium-coarse sand was 2.91, and the aggregate gradation was fair. The concrete strength was C60. The water reducer was a JKH-1 highly efficient powder water reducer (FDN) with a reducing rate of $18 \% \sim 25 \%$.

The fiber-reinforced polymer used in this test was carbon fiber-reinforced polymer (CFRP). The measured elastic modulus of the CFRP sheet was $234 \mathrm{GPa}$, the tensile strength was $2645.84 \mathrm{MPa}$, the thickness was $0.167 \mathrm{~mm}$, and the elongation was $1.08 \%$. The measured mechanical properties of reinforcement and concrete are shown in Tables 1 and 2.

2.2. Strengthening Scheme. The schematic diagram of the frame joint strengthened by the carbon fiber sheet is shown in Figure 2. Low cyclic loading was applied to simulate the earthquake load that damages the model of steel fiberreinforced high-strength concrete frame joints. The FRP sheet was used to reinforce the joint. The strengthening scheme was shown in Table 3.

The cracks on the surface of the concrete are located, the width is measured, and they are repaired. The small independent chinks with the width $\leq 0.2 \mathrm{~mm}$ should be repaired with a repair adhesive of good permeability and, then, sealed. For large independent and penetrating cracks, the periphery should be sealed first. Then, the high-strength repair adhesive could be applied. For a dormant crack of a width $\geq 0.5 \mathrm{~mm}$, the method was to fill up the crack. First, a $\mathrm{U}$-shape groove is chiseled along the crack with a concrete cutting disc. Then, the crack is cleaned with acetone, the grout nipple is pasted, and the crack is filled up with a sealant. Under the sustained compression made by the air compressor, the structural repair adhesive was injected into the cracks. The nooks of the beams were beveled by the structural adhesive. The surface was burnished with the sander when the adhesive was solidified.

Next, the damaged joints were reinforced by CFRP. The concrete surface was polished until the tectorium was removed and the smooth structure interface appears. Intensively mixed fat material was, then, spread on the concrete surface evenly with a brush, which should not be too thin. The processed fiber sheet was pasted to the due position and rolled with the special roller along the stress direction for several times till the connection resin was extruded from the fiber. By this, the bubble was squeezed out so that the fiber sheet was pressed closely to the concrete surface. Then, the impregnating resin was applied to the surface of the fiber sheet. The process mentioned above was repeated to paste more pieces of fiber sheet. The CFRP sheet, made by hand and by impregnating the substrate with fiber, was homemade CFRP.

2.3. Loading Scheme. The experiment applied a multichannel electrohydraulic servodynamic fatigue test system to conduct low cyclic loading. The pillar end would endure axial load from a $2000 \mathrm{kN}$ oil jack fixed on the heavy frame. First, the pillar top was put under the axial load from the oil jack. When the axial compression ratio reaches the predesigned 0.3, it was kept unchanged during the experiment. Then, low cyclic loading was applied by using the electrohydraulic servo actuator. The first two cycles load with control force, of which the first cycle loads to $75 \%$ of the yield load calculated value so as to simulate the stress condition in normal occasions. Since the key part of the study lied in the phase of plastic deformation, in the second cycle, the model was loaded directly to the yielded state. Displacement control was, then, used for loading. Staged loading was adopted according to the multiple of the displacement of the pillar end in the yielded state. At each displacement level, recycling was performed twice until the maximum load value of the $n$th cycle was lower than $85 \%$ of the highest load value when the model was damaged.

\section{Finite Element Analysis Model}

3.1. Constitutive Structure Relation of Materials. The axial compressive stress-strain curve of high-strength concrete used the Code for Design of Concrete Structures (GB 500102010) [10]. The tensile stress-strain relationship of highstrength concrete is described as follows: upper period as line and lower period as index. The elastic modulus before crack was the same as that of the initial elastic modulus after crack, and the concrete was considered as nonbrittle material. That was to say, the concrete tensile strength of the crack did not decline to zero immediately, but declined with the widening 
of the crack. For high-strength concrete, the parameter of the calculation formula was from reference $[11,12]$.

At the yielding period, the reinforcement's stress had a small change, but strain increased dramatically, and the stress-strain curve was a $0.01 E$ slope line, where $E$ was the elastic modulus of reinforcement. After the plastic hinge to form, the ultimate deformation of the plastic area concrete would seldom exceed 0.006 , so the deformation of reinforcement had a small change at the hardening period, and the stress-strain curve was a $0.01 E$ slope line, taking $E^{\prime}=$ $0.01 E$ [13]. As metal material, steel fiber took the ideal elastoplasticity stress-strain relationship as reinforcement. The damage of steel fiber concrete was mainly because of the pulling out of steel fiber from the concrete, not because of the broken of the steel fiber; therefore, the tensile stress was taken when steel fiber was pulling out as the tensile strength of steel fiber, and in this paper, it was taken as $250 \mathrm{MPa}$ [14].

\subsection{Concrete Failure Criterion and the Crack Treatment.} The concrete failure criterion took the William-Warnke model with five parameters, and the formula was $\left(F / f_{c}\right)-S \geq 0$. In this formula, $F$ was the function of the main stress $\sigma_{1}, \sigma_{2}$, and $\sigma_{3}, S$ was the destroying section of the main stress, and the five parameters, $f_{t}, f_{c}, f_{c b}, f_{1}$, and $f_{2}$, were uniaxial tensile strength, axial compressive strength, equal pressure biaxial compressive strength, biaxial compressive strength under hydrostatic pressure, and multiaxial compressive strength under ambient pressure, respectively. Also, the ANSYS method was used, when the ambient pressure was small, the failure surface could be made certain by two parameters $f_{t}$ and $f_{c}$, and the other three parameters were $f_{c b}=1.2 f_{c}, f_{1}=1.45 f_{c}$, and $f_{2}=1.725 f_{c}$ [15].

In analysis, the dispersion crack model was used to treat the frame joint cracking process. After cracks emerge, subsequent loading would produce sliding or shearing on the crack surface. In analysis, a split plane shear transfer coefficient $\left(\beta_{t}\right)$ when the crack opens and split plane transfer coefficient $\left(\beta_{c}\right)$ were introduced to simulate the loss of the concrete shearing capacity. $\beta_{t}$ had a great influence on the calculation result when the crack emerges, and generally, it was between $0.3 \sim 0.5$. The $\beta_{t}$ value of the shear member was small, the $\beta_{\mathrm{t}}$ value of the flexural member was large, and the frame node was the shear member, so the $\beta_{t}$ value was small, and in this paper, $\beta_{t}=0.3$. $\beta_{c}$ had a little influence on the result of the monotonic loading load-carrying specimen, and generally, it was between $0.9 \sim 1.0$, and in this paper, $\beta_{c}=0.9$. For not considering the concrete crush, it was hard to simulate the concrete failure process, and the normal failure surface would cause the premature crush invalidation. Therefore, this paper used the expanded crush plane to consider the restriction effect of the steel fiber to the concrete, and the axis compressive strength parameter of the failure criterion was $1.2 \cdot f_{c} \sim 2 \cdot f_{c}$.

3.3. Element Choosing. Reinforcement used Link 8, and concrete used Solid 65. The FRP sheet used shell 41 . The steel fibers were large in number, and also, they distribute in chaos, so it was impossible to model the role of each single steel fiber. Therefore, we take the steel fibers as distributing microreinforcements. They distribute into the concrete Solid 65 evenly according to volume ratio, and together with concrete, they compose an integral model, that is, steel fiber was distributed along with the axes of the coordinates, and in each direction, the volume ratio was distributed according to the unit side length ratio; also, the influence of the steel fiber distribution effective coefficient and orientation coefficient is considered. Moreover, the steel fiber tensile strength was the tensile strength when steel fiber was pulling out, so there was no need to consider the bond-slip between the steel fiber and the concrete. For the concrete and reinforcement, the discrete model was used for modeling. The bond-slip between the two uses Combin 39 to simulate, and the bond-slip constitutive construction relation uses the four line segment model advised by the CEB-FIPMC90 in reference [16].

For concrete and the CFRP sheet, the discrete model was used for modeling. The bond-slip between the two used Combin 39 to simulate. As the plane was perpendicular to the fiber direction of slip, the loading process did not occur, so in the analysis, it could correspond to nodes in the direction of coupled degrees of freedom, and it only needed to consider the vertical slip to the FRP and the slip along the fiber direction. The bond-slip curve between concrete and fiber cloth was based on the formula given in $[17,18]$. For the transversal U-shaped wrapped FRP sheet, it was assumed that the relative slip concrete was mainly along the beam height direction with respect to the FRP sheet and the joint of concrete and FRP sheet node displacement coupling in the other two directions.

3.4. Element Birth and Death. If materials need to be added or deleted in the structure during the finite element analysis, the life and death option of the element could be used to kill or activate the element. The element being killed was not to delete the element from the model, but to multiply the corresponding position in the overall stiffness matrix by a tiny factor, so that the element can be ignored, but the element still exists. The element activation was not to add elements to the model, but to reactivate the previously killed elements, that is, the corresponding position in the overall stiffness matrix was not multiplied by a small factor, at this time, the element attributes such as mass and stiffness will restore their original values, but there is no strain value $[19,20]$.

Since the reinforcement is based on the cracks of the frame joints, although the cracks had been repaired before reinforcement, there were still microcracks in the concrete. If the influence of the existing microcracks was not considered in the finite element analysis, the rigidity of the structure would be too large, which is inconsistent with the test results. Therefore, in the finite element analysis, the method of element birth and death was used to consider the influence of the existing microcracks. The CFRP element was killed in the load step before the cracking of the specimen, and the stress of the joint was analyzed according to that of the unreinforced frame. The CFRP element was reactivated in the load step after the crack is generated, and it was involved in the stress work. 


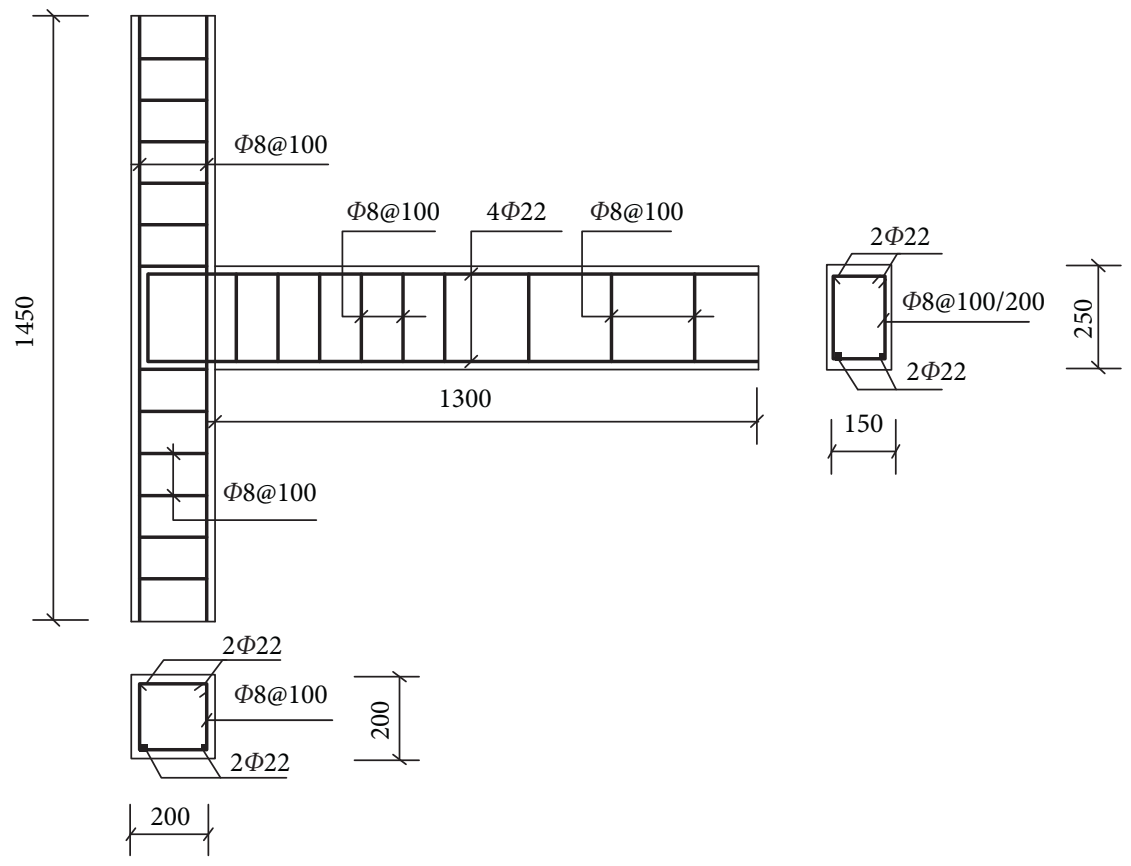

Figure 1: The sizes and reinforcements of the specimen (unit: $\mathrm{mm}$ ).

TABLE 1: Mechanical performance index of the steel bar.

\begin{tabular}{lccc}
\hline Rebar grade & Diameter $(\mathrm{mm})$ & Yield strength $(\mathrm{MPa})$ & Modulus of elasticity $(\mathrm{GPa})$ \\
\hline HPB235 & 8 & 312.87 & 203 \\
HPB335 & 22 & 373.68 & 203 \\
\hline
\end{tabular}

TABLE 2: Mechanical performance index of concrete.

\begin{tabular}{|c|c|c|c|c|c|}
\hline \multirow{2}{*}{ Model } & \multirow{2}{*}{ Concrete type } & \multicolumn{3}{|c|}{ Concrete strength } & \multirow{2}{*}{ Modulus of elasticity (GPa) } \\
\hline & & Cube strength $(\mathrm{MPa})$ & Axial compressive strength (MPa) & Tensile strength $(\mathrm{MPa})$ & \\
\hline \multirow{2}{*}{1} & HSC & 62.73 & 57.07 & 4.32 & 40.48 \\
\hline & FHSC & 64.43 & 58.56 & 4.61 & 41.09 \\
\hline \multirow[b]{2}{*}{2} & HSC & 58.64 & 50.88 & 3.91 & 40.75 \\
\hline & FHSC & 65.20 & 50.36 & 4.43 & 37.38 \\
\hline
\end{tabular}

HSC: high-strength concrete; FHSC: steel fiber high-strength concrete.

3.5. Mesh Partition. When we perform analysis by taking the whole model of joints, the size and the shape of the element mesh will both influence the analysis results. If the meshes were divided too meticulously, it will cause the instability of numerical calculation, and if the meshes were divided too coarsely, it will influence precision. Only the right meshes can get the convergence. By comparison, in this paper, mesh partition is performed by $5 \mathrm{~cm}$, and the corresponding mesh partition needs to satisfy certain geometry topology rule. As it was necessary to consider the thickness of the protective layer of the beam and the column, in this paper, besides $5.0 \mathrm{~cm}$, there were also $3.5 \mathrm{~cm}$ and $4.0 \mathrm{~cm}$. The finite element model is shown in Figure 3.
3.6. Boundary Conditions and Load Application. In order to simulate the form of joint destruction under the low cycle loading, we supplied the $X$-direction the two lateral surfaces of the upper and lower end of the column translation displacement constraint, supplied $X, Y, Z$ three directions translation displacement constraints at the lower end of the column, supplied $Y$ axial force at the column top end, and supplied $Y$ reversed force or displacement at the beam ends. In the nonlinear analysis, by defining load step and load substep, we divided the load into a series of load increments. To solve by finite element, we made a series of linear approaches in the load increments to achieve balance. Considering the nonlinear influence of steel fiber concrete, we adopt the 


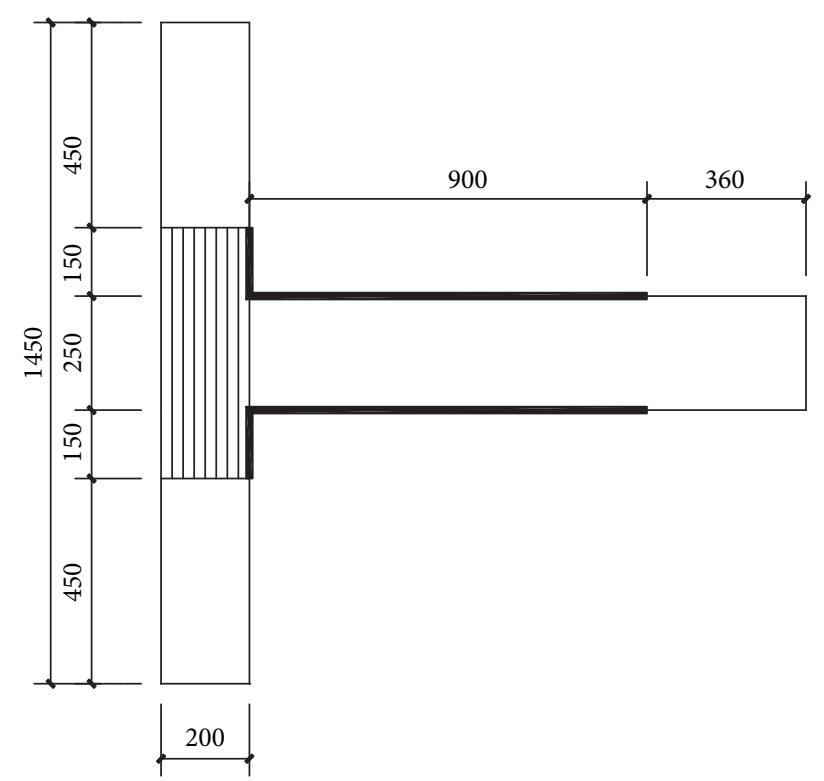

FIGURE 2: Sticking method and the range of CFRP (unit: $\mathrm{mm}$ ).

TABLE 3: Strengthening scheme of the joints.

\begin{tabular}{ll}
\hline Model & Strengthening scheme of the damaged model \\
\hline 1 & Treat the crack; paste one piece of FRP at the angle of $45^{\circ}$ across another piece in the core area; and paste two pieces of FRP at the \\
beam.
\end{tabular}

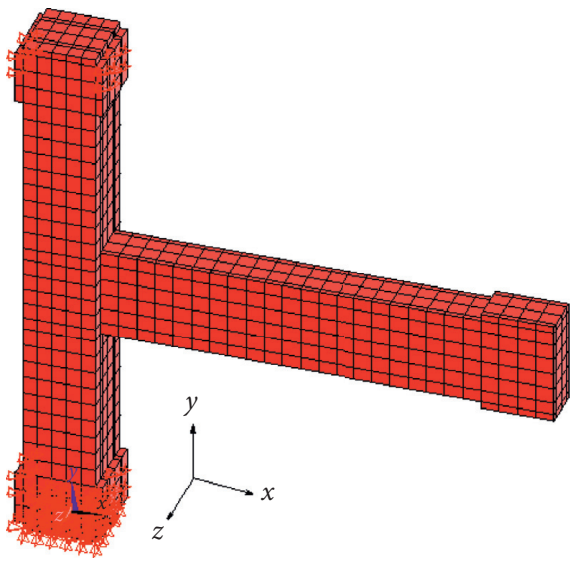

(a)

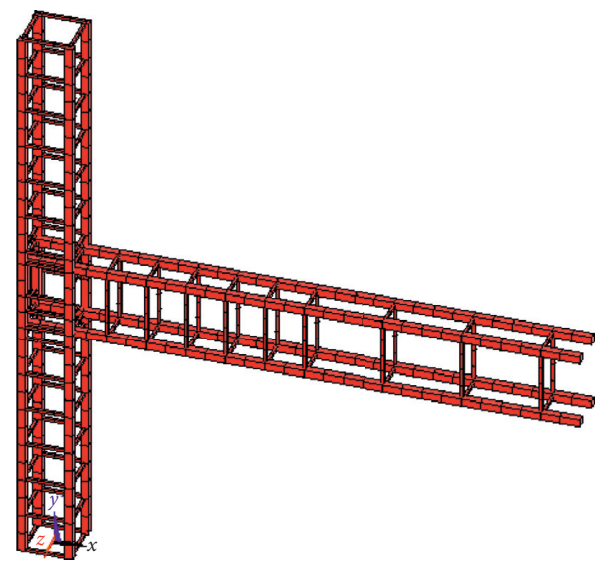

(b)

FIGURE 3: Finite element model of frame exterior joints. 
Newton-Raphson method doing nonlinear iteration. The displacement convergence criterion was used, and the convergence precision was $1 \%$. In order to improve the convergence of nonlinear analysis, adaptive descend gene, linear searching, forecasting, and dichotomy were used in this paper.

\section{Findings and Discussion}

Table 4 shows the comparative result of the damaged frame joints reinforced by FRP. According to the ratio of the experimental results and the analysis results, the average value of the yield load was 1.011, the standard deviation of the yield load was 0.043 , and the coefficient of variation of the yield load was 0.042 . The average value of the yield displacement was 1.049 , the standard deviation of the yield displacement was 0.064 , and the coefficient of variation of the yield displacement was 0.061 . The average value of the ultimate load was 0.963 , the standard deviation of the ultimate load was 0.087 , and the coefficient of variation of the ultimate load was 0.091 . The average value of the ultimate displacement was 1.066 , the standard deviation of the ultimate displacement was 0.074 , and the coefficient of variation of the ultimate displacement was 0.069. Thus, it showed that the analysis results and the experimental results match well.

According to the analysis results, the yield load of reinforced model 1 was 1.12 times of that before. The yield displacement of reinforced model 1 was 1.34 times of that before. The ultimate load of reinforced model 1 was 1.39 times of that before. The ultimate displacement of reinforced model 1 was 2.09 times of that before. Model 2 also presents a similar result. The yield load of reinforced model 2 was 1.26 times of that before. The yield displacement of reinforced model 2 was 2.13 times of that before. The ultimate load of reinforced model 2 was 1.37 times of that before. The ultimate displacement of reinforced model 2 was 1.63 times of that before. Thus, the yield load, yield displacement, ultimate load, and ultimate displacement are improved and all reach the original condition, which can meet the standard of seismic appraisal.

The major problem of reinforced model 1 was the crazing of the concrete along the margin of fiber sheet, while the problem of model 2 after strengthening was the rip of fiber sheet in the core area. Although the ultimate load of the two models was similar, the ultimate displacement of reinforced model 1 was larger than that of model 2 mainly because of the mechanical behavior and fiber direction of the fiber sheet. Model 2 with the fiber sheet pasted at $0^{\circ}$ vertically in the core area only provides vertical constraint, while model 1 with the cross fiber sheet enhances both vertical and horizontal deformation capability of the core area concrete.

4.1. Hysteretic Curve and Skeleton Curve. The hysteretic curve and skeleton curve of the damaged frame joints model strengthened by FRP are shown in Figures $4-11$. The skeleton curve of the concrete joint specimen could be obtained by connecting each load drop point of the loaddisplacement hysteretic curve, that is, the envelope line of the peak point of each stage of the load-displacement hysteretic curve. The load-displacement curve of the joint under the same loading was similar, which reflects the relationship between the loading and deformation of the joint, and was an important basis for the seismic performance analysis of the joint. The result showed that compared with the original model, the hysteretic curve of damaged joint model strengthened by FRP was fuller. Meanwhile, the ultimate load, ultimate displacement, and times of circulation all increased to some degree. The coverage of the skeleton curve enlarged, which met the standard of the seismic appraisal. For example, compared with original model 1, reinforced model 1 had a fuller hysteretic curve and more circulation times, whose ultimate load and ultimate displacement were 1.39 and 2.09 times, respectively, of that before. For reinforced model 2, the hysteretic curve was also fuller. The ultimate load and ultimate displacement were 1.37 and 1.63 times, respectively, of that before, while the circulation times remained the same.

Compared with reinforced model 2, reinforced model 1 had a fuller hysteretic curve, larger coverage of the skeleton curve and more circulation times. The ultimate load of model 1 was 0.95 times of model 2, and the ultimate displacement was 1.02 times of model 2 . The result indicated that the cross fiber sheet at the angle of $45^{\circ}$ exerts stronger constraint on the core area concrete than the vertical fiber sheet. The shear capacity and the deformation capacity of the joint core area were enhanced; thus, the energy dissipation capacity was improved.

4.2. Energy Dissipation Capacity. The energy dissipation capacity was the area surrounded by the load-deformation hysteretic curve. The energy dissipation capacity of damaged frame joints mode 1 reinforced by FRP is shown in Table 5. The result showed that, after reinforcement, the energy dissipation capacity of the model reaches the original level which meets the standard of seismic appraisal. For example, the dissipation energy and strain energy of reinforced model 1 were 4.58 times and 2.98 times of that before, respectively. The ratio of dissipation energy and strain energy was 1.53 times of that before. The dissipation energy and strain energy of reinforced model 2 were 2.13 times and 1.65 times of that before, respectively. The ratio of dissipation energy and strain energy was 1.30 times of that before.

The dissipation energy and strain energy of reinforced model 2 were 0.86 times of that of model 1 . The ratio of dissipation energy and strain energy of model 2 and model 1 was the same. The result indicates that the cross fiber sheet at the angle of $45^{\circ}$ exerts stronger constraint on the core area concrete than the vertical fiber sheet and, thus, enhances the energy dissipation capacity.

4.3. Displacement Ductility. The displacement ductility ratio was defined as the ultimate displacement divided by the yield displacement. The displacement ductility ratio of damaged 
TABLE 4: Result of the experiment and analysis.

\begin{tabular}{|c|c|c|c|c|c|c|c|c|c|c|}
\hline \multirow[b]{2}{*}{ Model } & \multicolumn{2}{|r|}{ YS } & \multicolumn{2}{|r|}{ US } & \multirow[b]{2}{*}{ Condition } & \multirow[b]{2}{*}{ Means } & \multicolumn{4}{|c|}{$\mathrm{AR} / \mathrm{BR}$} \\
\hline & $\begin{array}{l}\text { Load } \\
(\mathrm{kN})\end{array}$ & $\begin{array}{c}\text { Displacement } \\
(\mathrm{mm})\end{array}$ & $\begin{array}{l}\text { Load } \\
(\mathrm{kN})\end{array}$ & $\begin{array}{c}\text { Displacement } \\
(\mathrm{mm})\end{array}$ & & & $\begin{array}{c}\text { YS } \\
\text { load }\end{array}$ & $\begin{array}{c}\text { YS } \\
\text { displacement }\end{array}$ & $\begin{array}{l}\text { US } \\
\text { load }\end{array}$ & $\begin{array}{c}\text { US } \\
\text { displacement }\end{array}$ \\
\hline \multirow{4}{*}{1} & 36.00 & 8.98 & 47.39 & 17.89 & BR & \multirow{2}{*}{ Experiment } & \multirow{2}{*}{1.01} & \multirow{2}{*}{1.56} & \multirow{2}{*}{1.12} & \multirow{2}{*}{2.34} \\
\hline & 36.52 & 14.03 & 53.07 & 41.91 & $\mathrm{AR}$ & & & & & \\
\hline & 34.04 & 10.37 & 40.27 & 19.92 & BR & \multirow{2}{*}{ Analysis } & \multirow{2}{*}{1.12} & \multirow{2}{*}{1.34} & \multirow{2}{*}{1.39} & \multirow{2}{*}{2.09} \\
\hline & 38.04 & 13.86 & 56.10 & 41.67 & AR & & & & & \\
\hline \multirow{4}{*}{2} & 30.06 & 7.40 & 47.44 & 25.14 & $\mathrm{BR}$ & \multirow{2}{*}{ Experiment } & \multirow{2}{*}{1.20} & \multirow{2}{*}{2.18} & \multirow{2}{*}{1.19} & \multirow{2}{*}{1.39} \\
\hline & 35.98 & 16.14 & 56.66 & 35.05 & $\mathrm{AR}$ & & & & & \\
\hline & 30.06 & 7.69 & 42.98 & 24.98 & $\mathrm{BR}$ & \multirow{2}{*}{ Analysis } & \multirow{2}{*}{1.26} & \multirow{2}{*}{2.13} & \multirow{2}{*}{1.37} & \multirow{2}{*}{1.63} \\
\hline & 37.96 & 16.36 & 58.88 & 40.72 & AR & & & & & \\
\hline
\end{tabular}

YS- yield state, US- ultimate state, BR- before reinforcement, AR- after reinforcement.

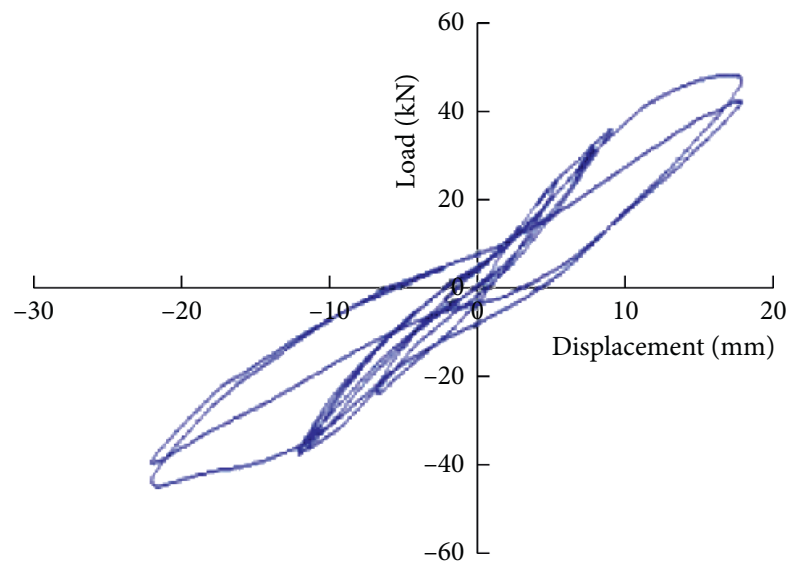

(a)

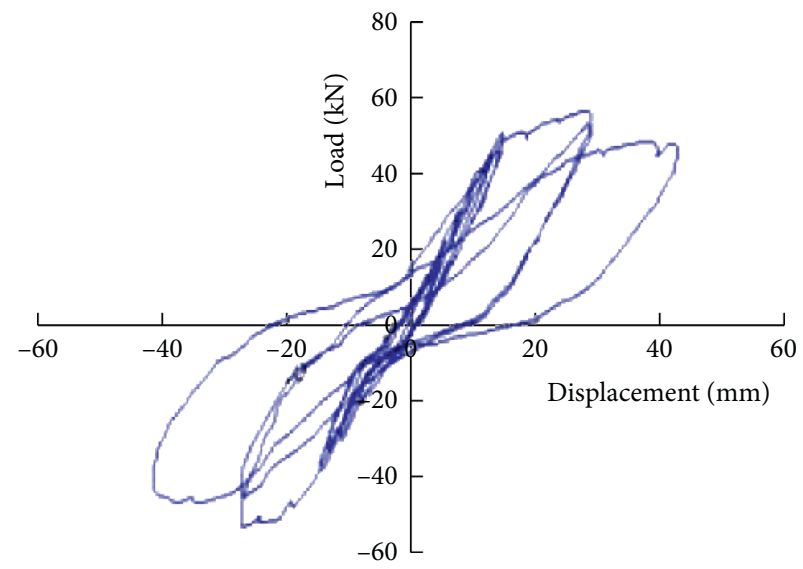

(b)

FIGURE 4: Comparison of the hysteretic curves of model 1 (experimental results): (a) before reinforcement; (b) after reinforcement.

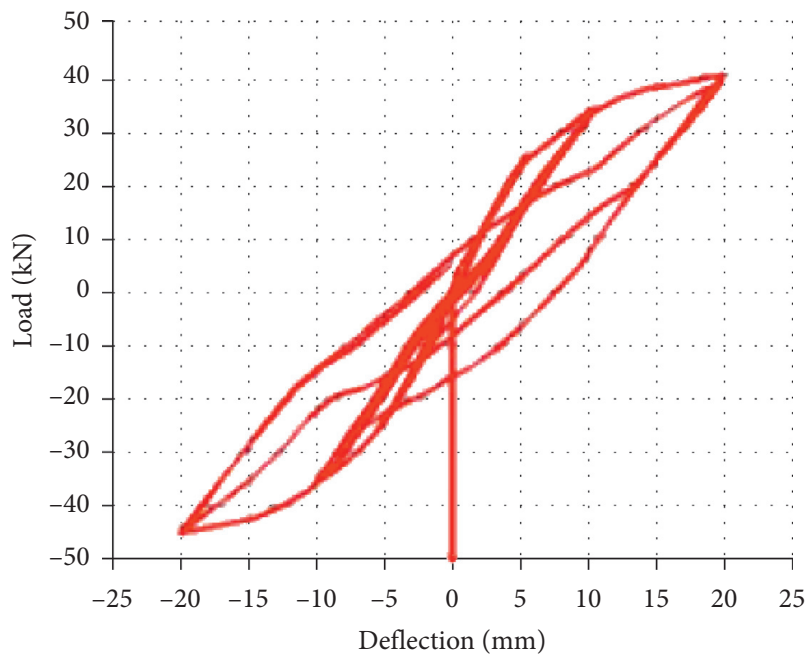

(a)

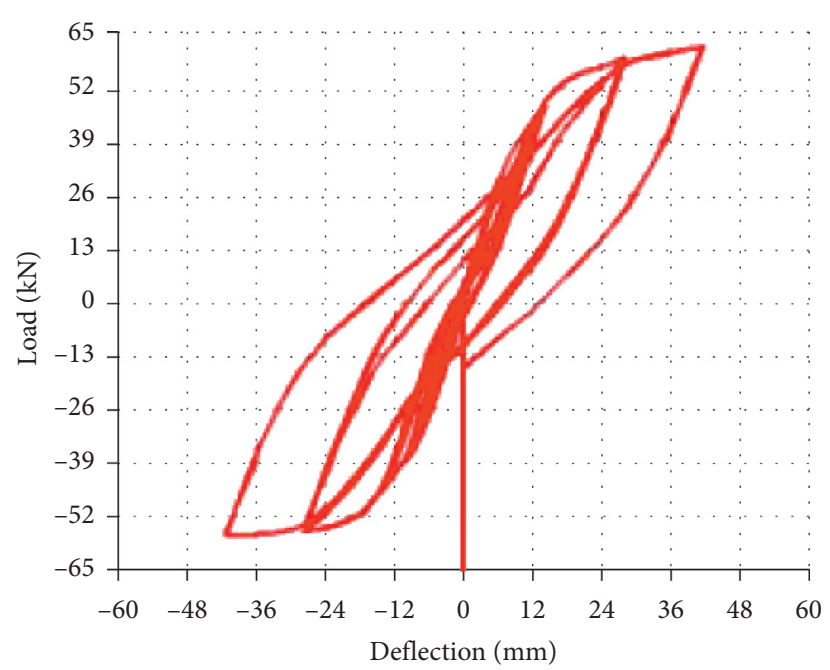

(b)

FIGURE 5: Comparison of the hysteretic curves of model 1 (analysis results): (a) before reinforcement; (b) after reinforcement. 


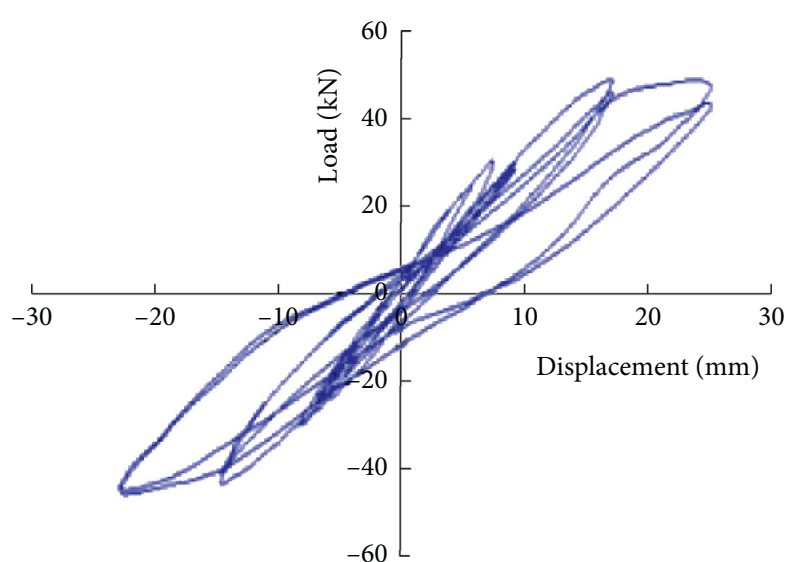

(a)

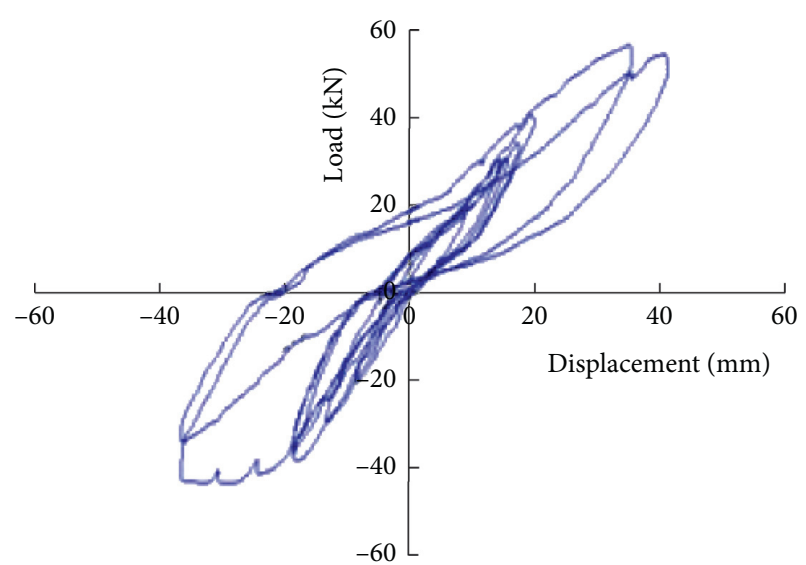

(b)

Figure 6: Comparison of the hysteretic curves of model 2 (experimental results): (a) before reinforcement; (b) after reinforcement.

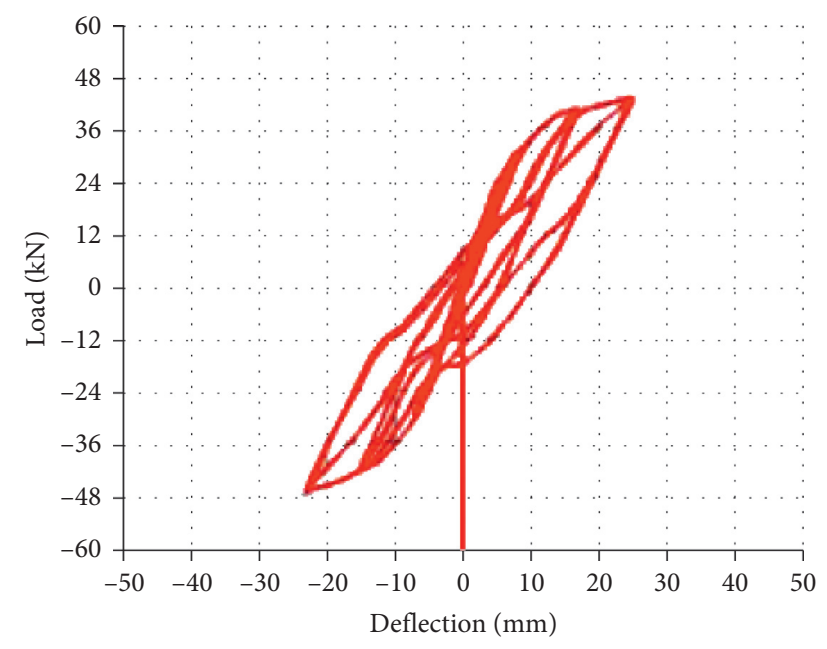

(a)

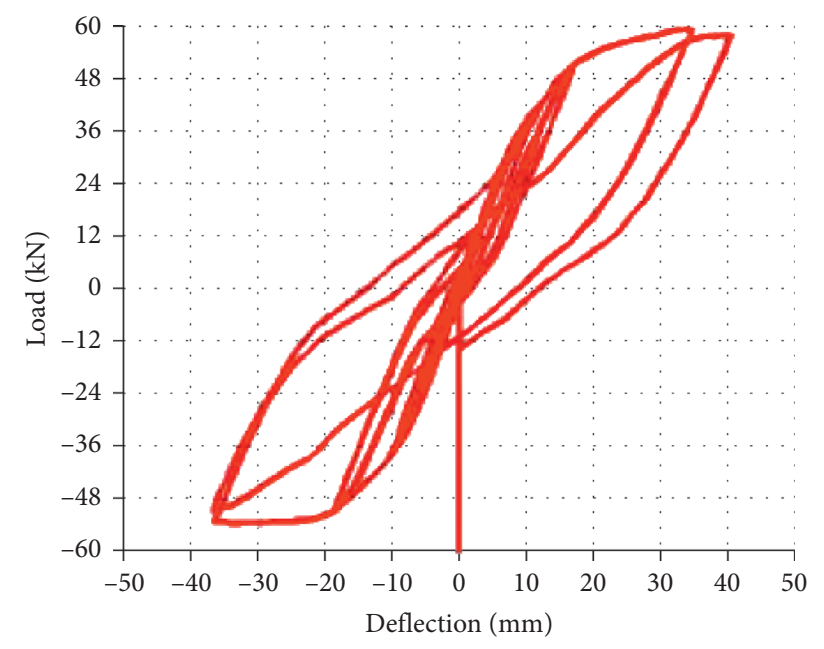

(b)

FIGURE 7: Comparison of the hysteretic curves of model 2 (analysis results): (a) before reinforcement; (b) after reinforcement.

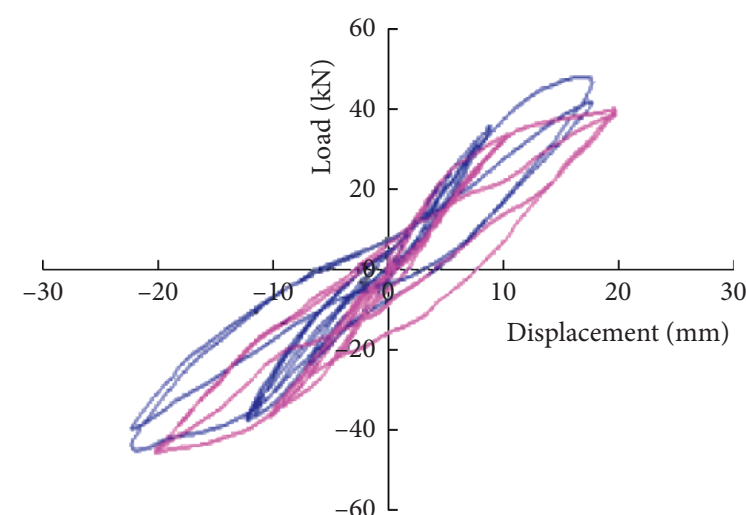

Experiment
- Analysis
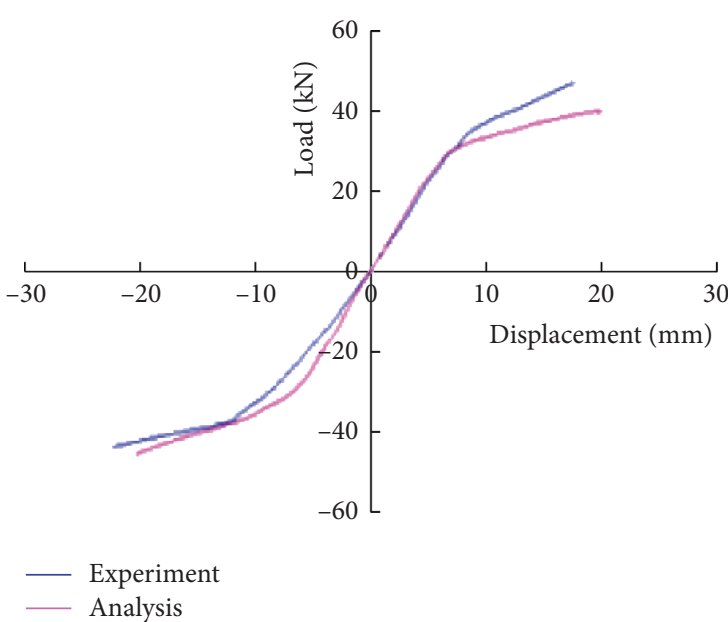

(a)

(b)

Figure 8: Comparison of the hysteretic curves and skeleton curve of model 1 (before): (a) hysteretic reinforcement; (b) skeleton reinforcement. 


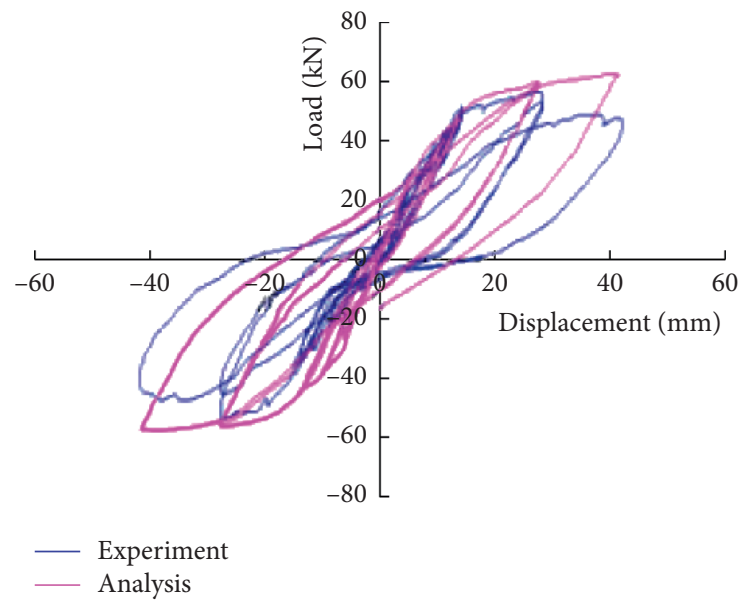

(a)

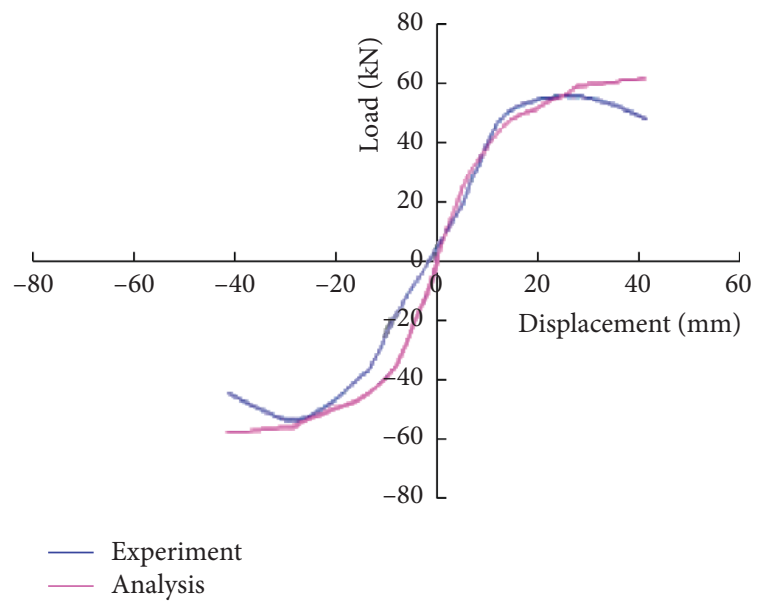

(b)

Figure 9: Comparison of the hysteretic curves and skeleton curve of model 1 (after): (a) hysteretic reinforcement; (b) skeleton reinforcement.

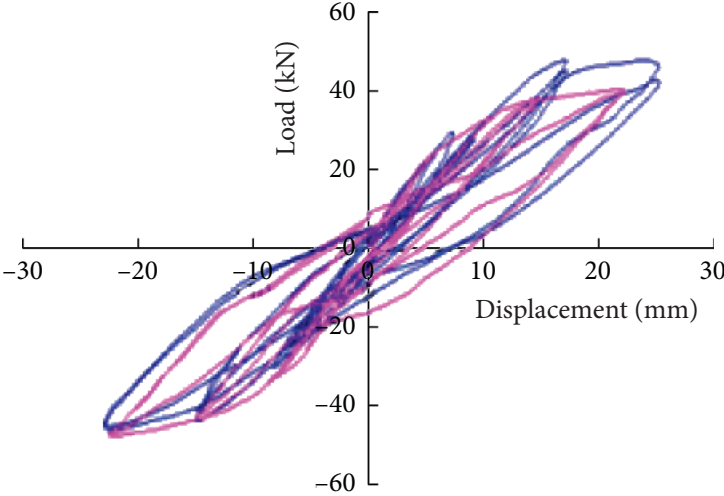

Experiment
Analysis

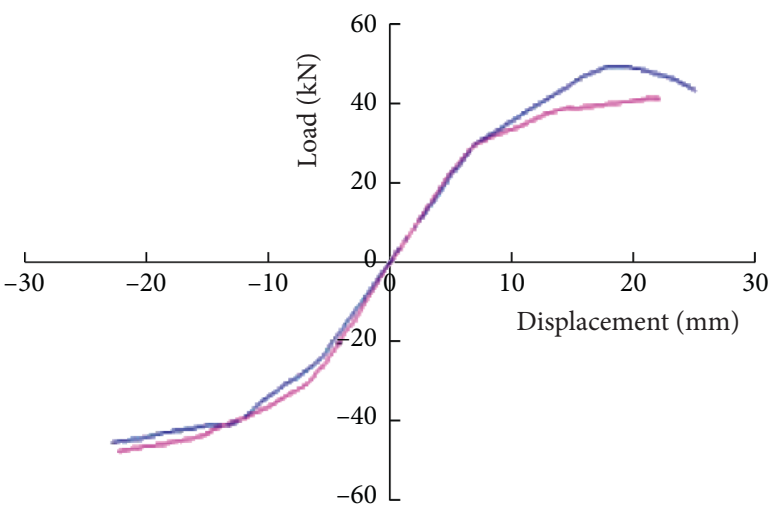

- Experiment

(a)

(b)

Figure 10: Comparison of the hysteretic curves and skeleton curve of model 2 (before): (a) hysteretic reinforcement; (b) skeleton reinforcement.

frame joints reinforced by FRP is shown in Table 6. The results showed that, for model 1 , the yield displacement, ultimate displacement, and displacement ductility ratio after reinforcement were 1.34 times, 2.09 times, and 1.57 times of that before reinforcement, respectively. For model 2, the yield displacement, ultimate displacement, and displacement ductility ratio after reinforcement were 2.13 times, 1.63 times, and 0.77 times of that before reinforcement, respectively. The result showed that the displacement ductility of the model with the cross fiber sheet at the angle of $45^{\circ}$ meets the standard of seismic appraisal, but the model with the fiber sheet at the angle of $0^{\circ}$ proves a bad displacement ductility.
4.4. Bearing Capacity Degeneration. The reduction coefficient of bearing capacity was expressed by the ratio of the peak value of the second cycle load to the peak value of the first cycle load. The bearing capacity reduction coefficient of the damaged frame joints reinforced by FRP is shown in Table 7. The result showed that different methods of reinforcement barely lead to any differences of the bearing capacity reduction. For example, when displacement was $\Delta y$, the bearing capacity reduction coefficient of model 1 was 0.97 times of that before, while the number of model 2 was 1.00. When the displacement was $2 \Delta y$, the bearing capacity reduction coefficient of model 1 was 0.98 times of that before, while that of model 2 was 0.98 . When the 


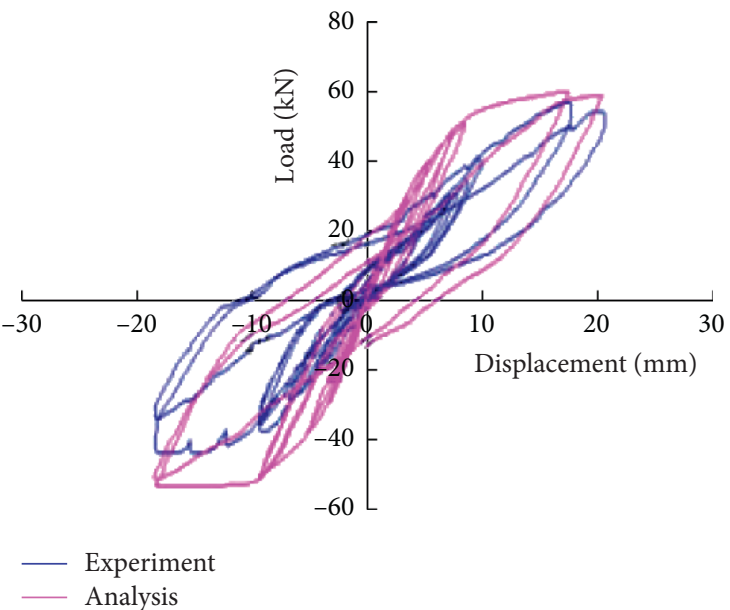

(a)

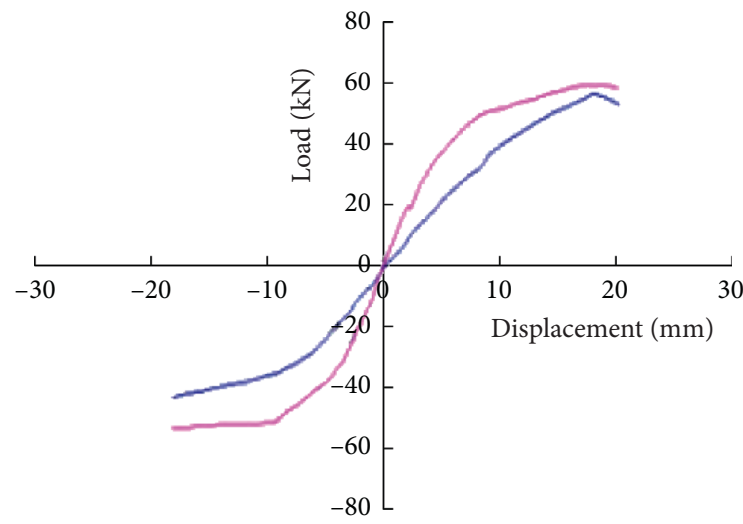

- Experiment

— Analysis

Figure 11: Comparison of the hysteretic curves and skeleton curve of model 2 (after): (a) hysteretic reinforcement; (b) skeleton reinforcement.

TABLE 5: The energy dissipation capacity of joints.

\begin{tabular}{|c|c|c|c|c|c|c|c|c|}
\hline \multirow{2}{*}{ Model } & \multirow{2}{*}{$\mathrm{DE}(\mathrm{kN} \cdot \mathrm{mm})$} & \multirow{2}{*}{$\mathrm{SE}(\mathrm{kN} \cdot \mathrm{mm})$} & \multirow{2}{*}{$\mathrm{DE} / \mathrm{SE}$} & \multirow{2}{*}{ Condition } & \multirow{2}{*}{ Means } & \multicolumn{3}{|c|}{$\mathrm{AR} / \mathrm{BR}$} \\
\hline & & & & & & $\mathrm{DE}$ & SE & $\mathrm{DE} / \mathrm{SE}$ \\
\hline \multirow{4}{*}{1} & 1344.1 & 3394.2 & 0.4 & $\mathrm{BR}$ & \multirow{2}{*}{ Experiment } & \multirow{2}{*}{3.86} & \multirow{2}{*}{2.61} & \multirow{2}{*}{1.48} \\
\hline & 5194.7 & 8870.9 & 0.59 & $\mathrm{AR}$ & & & & \\
\hline & 1184.3 & 3504.0 & 0.34 & $\mathrm{BR}$ & \multirow{2}{*}{ Analysis } & \multirow{2}{*}{4.58} & \multirow{2}{*}{2.98} & \multirow{2}{*}{1.53} \\
\hline & 5424.0 & 10438.2 & 0.52 & $\mathrm{AR}$ & & & & \\
\hline \multirow{4}{*}{2} & 2160.7 & 5314.9 & 0.41 & $\mathrm{BR}$ & \multirow{2}{*}{ Experiment } & \multirow{2}{*}{1.93} & \multirow{2}{*}{1.42} & \multirow{2}{*}{1.34} \\
\hline & 4161.1 & 7559.1 & 0.55 & $\mathrm{AR}$ & & & & \\
\hline & 2175.9 & 5424.0 & 0.4 & $\mathrm{BR}$ & \multirow{2}{*}{ Analysis } & \multirow{2}{*}{2.13} & \multirow{2}{*}{1.65} & \multirow{2}{*}{1.30} \\
\hline & 4643.0 & 8948.9 & 0.52 & $\mathrm{AR}$ & & & & \\
\hline
\end{tabular}

DE- dissipation energy; SE- strain energy.

Table 6: Displacement ductility of joints.

\begin{tabular}{|c|c|c|c|c|c|c|c|c|}
\hline \multirow{2}{*}{ Model } & \multirow{2}{*}{$\mathrm{YD}(\mathrm{mm})$} & \multirow{2}{*}{$\mathrm{UD}(\mathrm{mm})$} & \multirow{2}{*}{ DDR } & \multirow{2}{*}{ Condition } & \multirow{2}{*}{ Means } & \multicolumn{3}{|c|}{$\mathrm{AR} / \mathrm{BR}$} \\
\hline & & & & & & YD & UD & DDR \\
\hline \multirow{4}{*}{1} & 8.98 & 17.89 & 1.99 & $\mathrm{BR}$ & \multirow{2}{*}{ Experiment } & \multirow{2}{*}{1.56} & \multirow{2}{*}{2.34} & \multirow{2}{*}{1.50} \\
\hline & 14.03 & 41.91 & 2.99 & $\mathrm{AR}$ & & & & \\
\hline & 10.37 & 19.92 & 1.92 & $\mathrm{BR}$ & \multirow{2}{*}{ Analysis } & \multirow{2}{*}{1.34} & \multirow{2}{*}{2.09} & \multirow{2}{*}{1.57} \\
\hline & 13.86 & 41.67 & 3.01 & $\mathrm{AR}$ & & & & \\
\hline \multirow{4}{*}{2} & 7.40 & 25.14 & 3.40 & $\mathrm{BR}$ & \multirow{2}{*}{ Experiment } & \multirow{2}{*}{2.18} & \multirow{2}{*}{1.39} & \multirow{2}{*}{0.64} \\
\hline & 16.14 & 35.05 & 2.17 & $\mathrm{AR}$ & & & & \\
\hline & 7.69 & 24.98 & 3.25 & $\mathrm{BR}$ & \multirow{2}{*}{ Analysis } & \multirow{2}{*}{2.13} & \multirow{2}{*}{1.63} & \multirow{2}{*}{0.77} \\
\hline & 16.36 & 40.72 & 2.49 & $\mathrm{AR}$ & & & & \\
\hline
\end{tabular}

YD- yield displacement; UD- ultimate displacement; DDR- displacement ductility ratio.

displacement was $3 \Delta y$, Model 2 was damaged, which was reinforced. From this, we see that the bearing capacity reduction of the models after the reinforcement was worse than before. 
TABLE 7: Comparison of bearing capacity reduction coefficient of joints.

\begin{tabular}{|c|c|c|c|c|c|c|c|c|c|c|c|}
\hline \multirow{2}{*}{ Model } & \multirow{2}{*}{$\mathrm{YL}(\mathrm{kN})$} & \multirow{2}{*}{$\mathrm{UL}(\mathrm{kN})$} & \multirow{2}{*}{$\Delta y$} & \multirow{2}{*}{$2 \Delta y$} & \multirow{2}{*}{$3 \Delta y$} & \multirow{2}{*}{ Condition } & \multirow{2}{*}{ Means } & \multicolumn{4}{|c|}{$\mathrm{AR} / \mathrm{BR}$} \\
\hline & & & & & & & & YL & UL & $\Delta y$ & $2 \Delta y$ \\
\hline \multirow{4}{*}{1} & 36.00 & 47.39 & 0.969 & 0.901 & - & BR & \multirow{2}{*}{ Experiment } & \multirow{2}{*}{1.01} & \multirow{2}{*}{1.12} & \multirow{2}{*}{0.97} & \multirow{2}{*}{1.03} \\
\hline & 36.52 & 53.07 & 0.937 & 0.930 & - & $\mathrm{AR}$ & & & & & \\
\hline & 34.04 & 40.27 & 0.996 & 0.969 & - & $\mathrm{BR}$ & \multirow{2}{*}{ Analysis } & \multirow{2}{*}{1.12} & \multirow{2}{*}{1.39} & \multirow{2}{*}{0.97} & \multirow{2}{*}{0.98} \\
\hline & 38.04 & 56.10 & 0.967 & 0.946 & - & $\mathrm{AR}$ & & & & & \\
\hline \multirow{4}{*}{2} & 30.06 & 47.44 & 0.949 & 0.950 & 0.909 & $\mathrm{BR}$ & \multirow{2}{*}{ Experiment } & \multirow{2}{*}{1.20} & \multirow{2}{*}{1.19} & \multirow{2}{*}{1.01} & \multirow{2}{*}{1.01} \\
\hline & 35.98 & 56.66 & 0.963 & 0.957 & - & $\mathrm{AR}$ & & & & & \\
\hline & 30.06 & 42.98 & 0.993 & 0.977 & 0.982 & $\mathrm{BR}$ & \multirow{2}{*}{ Analysis } & \multirow{2}{*}{1.26} & \multirow{2}{*}{1.37} & \multirow{2}{*}{1.00} & \multirow{2}{*}{0.98} \\
\hline & 37.96 & 58.88 & 0.994 & 0.956 & - & AR & & & & & \\
\hline
\end{tabular}

YL- yield load; UL- ultimate load.

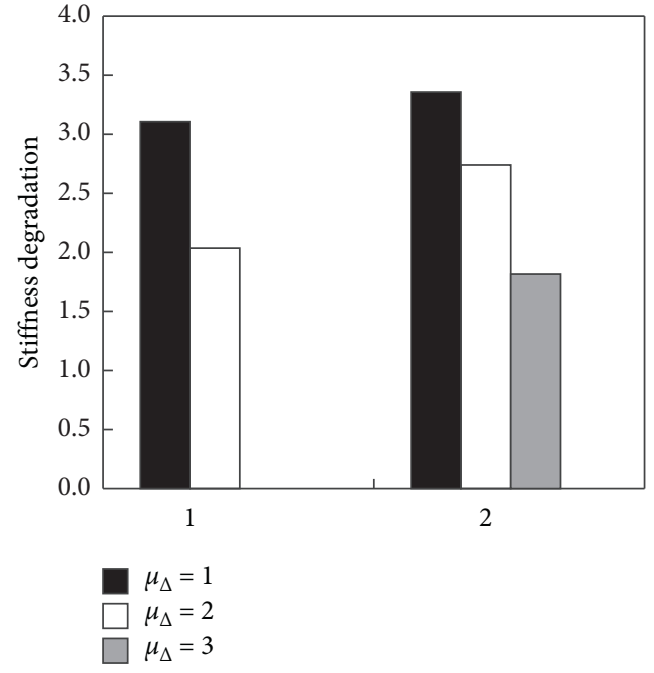

(a)

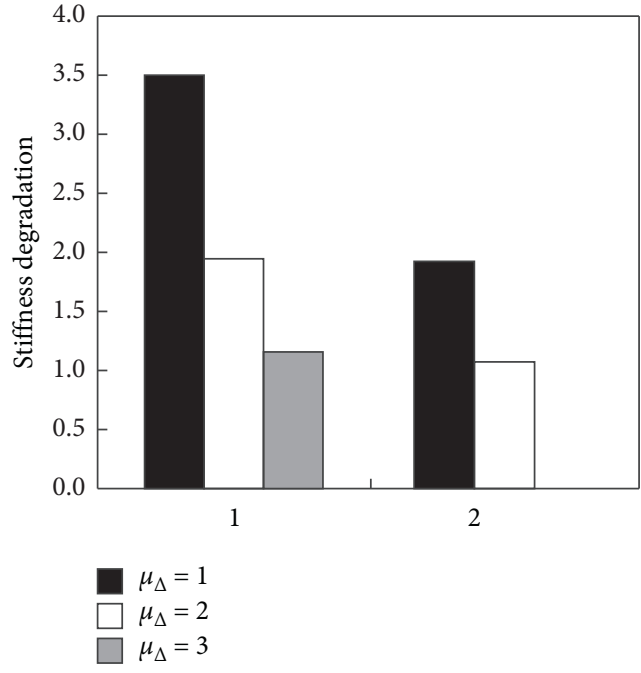

(b)

FIGURE 12: Stiffness comparison of joints (experimental results): (a) before reinforcement; (b) after reinforcement.

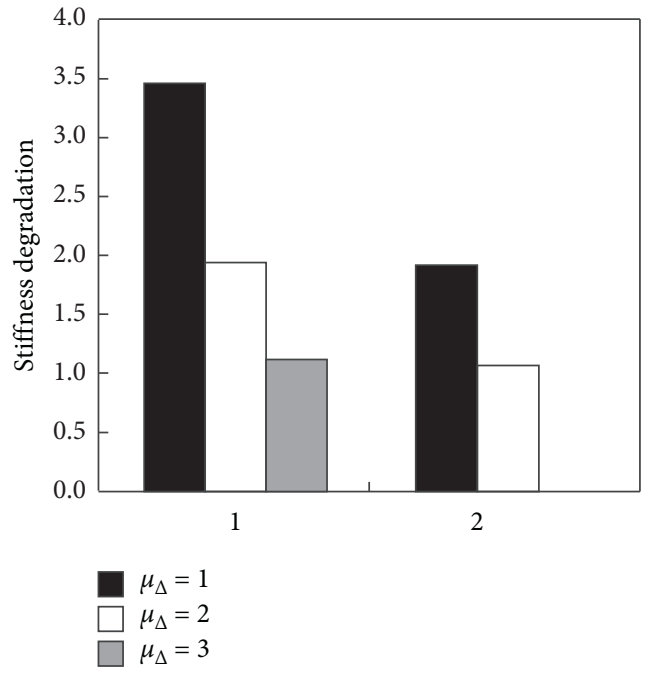

(a)

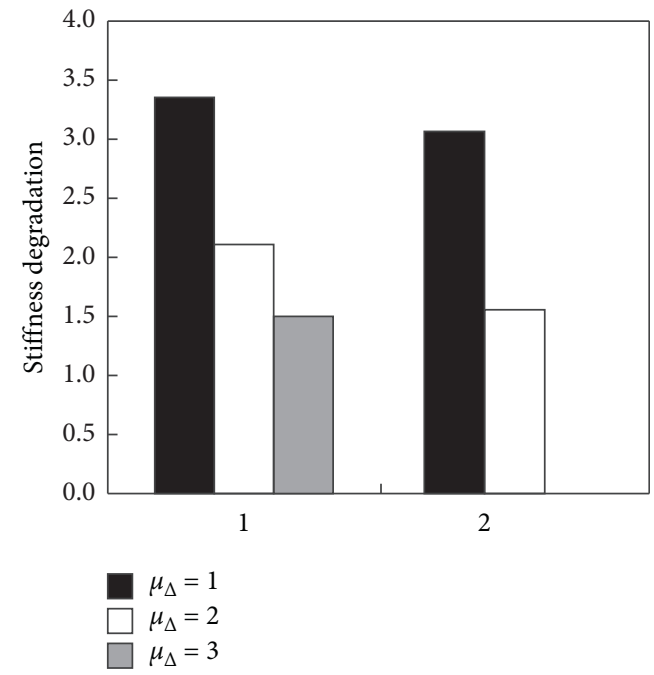

(b)

FIGURE 13: Stiffness comparison of joints (analysis results): (a) before reinforcement; (b) after reinforcement. 
4.5. Stiffness Degradation. In this paper, the stiffness used for stiffness degradation was loop stiffness. It was calculated by the displacement corresponding to the peak load ratio of each loading cycle. The loop and linear stiffness of the damaged frame joint model reinforced by FRP are shown in Figures 12 13. At every ductility factor, the stiffness of model 2 was lower than that of model 1 , and the circulation times of model 2 were fewer than those of model 1 . The result indicated that the stiffness of the reinforced model with the cross fiber sheet at the angle of $45^{\circ}$ meets the standard of seismic appraisal, but the model with the fiber sheet at the angle of $0^{\circ}$ degenerates fast.

\section{Conclusions}

Based on the seismic performance test and finite element analysis of damaged steel fiber-reinforced high-strength concrete frame joints strengthened by FRP under low cyclic repeated load, the following conclusions are drawn:

Pasting the carbon fiber sheet at the angle of $45^{\circ}$ in the core area after crack treatment can lead to better reinforcement performance than at $0^{\circ}$.

Although these two methods exert a little influence on the degradation of bearing capacity, the pasted fiber sheet increases the constraint of the core area concrete so that the bearing capacity, as well as the energy dissipation capacity, of the model was enhanced.

The strengthening method of pasting the carbon fiber sheet at $45^{\circ}$ in the joint core area prevents the rigidity degeneration and improves the displacement ductility of the model. On the contrary, the method of pasting the carbon fiber sheet at $0^{\circ}$ speeds up the rigidity degeneration and reduces the displacement ductility.

The finite element analysis result proves the rationality of the element type, material constitutive relation, and failure criterion used in the finite element analysis.

\section{Data Availability}

The data used in this study can be obtained from the corresponding author on request.

\section{Conflicts of Interest}

The authors declare no conflicts of interest.

\section{Acknowledgments}

The authors sincerely thank Professor Gao Danying of Zhengzhou University for the guidance and help. The research presented in this paper was supported by the National Natural Science Foundation of China (No. 50678159).

\section{References}

[1] M. J. Shannag, N. Abu-Dyya, and G. Abu-Farsakh, "Lateral load response of high performance fiber reinforced concrete beam-column joints," Construction and Building Materials, vol. 19, no. 7, pp. 500-508, 2005.

[2] M. Gencoqlu, "The effects of stirrups and the extents of regions used SFRC in exterior beam-column joints," Structural Engineering and Mechanics, vol. 27, no. 2, pp. 223-241, 2007.

[3] B. S. Hamad and C. D. B. Abs, "Effect of fiber-reinforced polymer confinement on bond strength of hooked bars in high-strength concrete," ACI Structural Journal, vol. 106, no. 6, pp. 831-839, 2009.

[4] D. Gao and J. Zhang, "Experimental investigation on seismic behavior of steel fiber reinforced high-strength concrete frame exterior joints," Industrial Construction, vol. 42, no. 5, pp. 84-89+28, 2012.

[5] J. Zhang and T. Wang, "Experimental investigation on seismic behavior of high-strength concrete frame exterior joints partially reinforced by steel fiber," Concrete, no. 7, pp. 13-16, 2011.

[6] T. Wang and J. Zhang, "The seismic behavior of steel fiber reinforced high-strength concrete frame joints," Disaster Advances, vol. 5, no. 4, pp. 1418-1423, 2012.

[7] T. Y. Wang, J. W. Zhang, and D. Y. Gao, "The seismic behavior of high-strength concrete frame joints," Applied Mechanics and Materials, vol. 238, pp. 838-843, 2012.

[8] J. Zhang, X. Tian, T. Wang, and D. Gao, "Influence of FRP material types on seismic behavior of FRP reinforced damaged steel fiber reinforced high-strength concrete frame exterior joints," Concrete, vol. 9, no. 8, pp. 24-28, 2013.

[9] A. Bousselham, "State of research on seismic retrofit of RC beam-column joints with externally bonded FRP," Journal of Composites for Construction, vol. 14, no. 1, pp. 49-61, 2010.

[10] National Standards of the People's Republic of China, Code for Design of Concrete Structures (GB50010-2010), China Architecture\& Building Press, Beijing, China, 2010.

[11] G. Zhenhai, "Strength and deformation of concrete," Journal of Tongji University, vol. 25, no. 3, pp. 255-261, 1997, in Chinese.

[12] Z. Yang and C. Wu, "Analysis on the seismic performance of RC frame beam-column joints strengthened by sprayed FRP," Applied Mechanics and Materials, vol. 578-579, pp. 835-838, 2014.

[13] Z. P. Liu, Nonlinear Numerical Simulation of Pre-Stressed Concrete and Reinforced Concrete Beam Based on ANSYS, Xinjiang Agricultural University, Xinjiang, China, 2007.

[14] G. Zhao, S. Peng, and C. Huang, Steel Fiber Reinforced Concrete Structures, ROC Military Academy, Kaohsiung, Taiwan, China, 1999.

[15] S. Moaveni, Finite Element Analysis: Theory and Application with ANSYS, Minnesota State University, Mankato, China, Fourth edition, 2015.

[16] B.-J Si, Z.-G. Sun, Q.-H. Ai, and D. Wang, "Sensitive analysis and model modification for finite element analysis of R/C bridge piers under cyclic loading," Engineering Mechanics, vol. 26, no. 1, pp. 174-180+186, 2009.

[17] L. De Lorenzis, B. Miller, and A. Nanni, "Bond of fiberreinforced polymer laminates to concrete," ACI Materials Journal, vol. 98, no. 3, pp. 256-264, 2001.

[18] K. T. Lau, P. K. Dutta, L. M. Zhou, and D. Hui, "Mechanics of bonds in an FRP bonded concrete beam," Composites Part B: Engineering, vol. 32, no. 6, pp. 491-502, 2001.

[19] S. Peng, C. Xu, M. Lu, and J. Yang, "Experimental research and finite element analysis on seismic behavior of CFRPstrengthened seismic-damaged composite steel-concrete frame columns," Engineering Structures, vol. 155, pp. 50-60, 2018. 
[20] H. T. Liu and T. Y. Wang, "Experimental study and finite element analysis of the seismic behaviors for steel fiber reinforced high-strength concrete frame exterior joints," Advanced Materials Research, vol. 295-297, pp. 1499-1504, 2011. 